III.

\title{
A Case of Probable Injury to the Ureter During Hysterectomy.
}

By J. C. Holdrch Leicester, M.D., B.S., B.Sc., M.R.C.P. (Lond.), F.R.G.S. (Eng.),

Indian Medical Service.

Mrs. C., European, aged 45 years, was admitted to the General Hospital, Calcutta, under my care on March 31, 1908. She gave the following history:- Menstruation had been quite regular up to January 16, 1909 (with the exception that she had missed two periods in 1907), occurring each month on or about the same date, lasting 5 days, and unaccompanied by pain. In February there was no period, but a blood discharge came on on March 2 and continued up to the date of admission (i.e., for 29 days), being very profuse, with the passage of a good many clots, and accompanied with severe backache.

Previous to this last period there had never been any flooding, nor had she ever suffered from backache. At no time had there been any intermenstrual discharge whatever.

She had had 3 children (the last 17 years ago) and no miscarriages.

There was nothing in the previous or family history of any bearing on the case.

State on admission. The abdomen is thickly covered with adipose tissue; nothing abnormal can be felt.

Per vaginam. Perineorrhaphy has been performed, but the result is not satisfactory, the posterior portion has given way completely, and the anterior part consists of a mere bridge of skin and subcutaneous tissue. The uterus is high up, quite freely movable and a little enlarged; the external os is somewhat patulous; nothing abnormal is detected in either fornix. There is free bleeding during examination.

On April 2 chloroform was administered, the cervix was dilated with Ramsay's dilators sufficiently to admit of the introduction of the index finger; there was free bleeding during dilatation. On digital exploration a ragged ulcerated surface was felt to the right and in front, the uterus was gently curetted in order to obtain a piece of tissue for examination.

The bridge of skin over the perineum having been divided a perineorrhaphy was performed. 
A good deal of bleeding occurred after the operation which was checked by the administration of ergot, and there was some fever for the first five days, the temperature fluctuating between $99^{\circ}$ and $100^{\circ}$.

The stitches were removed from the perineum on April 11, healing having taken place with a satisfactory result.

A microscopic examination of the curetted tissue was kindly made for me by Major Leonard Rogers, I.M.S., who reported: "The mass consists entirely of columnar epithelial tubes and small-celled infiltration as in cancer."

On April 14 a total hysterectomy was performed by the abdominal route, the uterus and cervix, together with the tubes and ovaries being widely remored. The peritoneal flaps were brought together by a continuous catgut suture and the abdominal wall was closed in layers. No enlarged glands were detected anywhere in the pelvis.

On opening the uterus after removal a superficial ragged ulcer, about the size of sixpence, was seen on the right side just above the internal os. The left ovary was enlarged and cystic, the right ovary somewhat small and fibrotic. The left tube was slightly inflamed, the right one normal.

There was a sharp rise of temperature immediately after the operation, followed by fever, which lasted up to May 6 .

Convalescence was slow but satisfactory except for the fever. The bowels were freely opened on April 16, and at no time was there any trouble connected with the urinary organs.

On April 19, and again on the following day, the patient had a rigor; the blood was examined for malarial parasites with a negative result. There was a scanty vaginal discharge which was perfectly sweet.

On the 23rd the stitches were removed, and the skin incision had healed well.

On the 24th there was a third rigor, the temperature rising to $104^{\circ} \mathrm{F}$.

On May 6 a slight pus discharge appeared from the centre of the sound, and on enlarging the opening from which this diseharge came an abscess was found just below the layer on the front of the rectus sheath, this was evacuated and a tube inserted.

The thickness of the fat on the abdominal wall may perhaps account for no evidence of this abscess being found earlier.

The wound was dressed daily but did not heal finally until June 25.

After the opening of this abscess there was no more fever until the evening of May 9 , when the temperature rose to $99.6^{\circ}$.

On May 10 (i.e., 26 days after the hysterectomy) a profuse vaginal discharge, clear and inoffensive, began, and concurrently with the onset of this discharge the temperature rose to $101^{\circ} \mathrm{F}$. On May 21 
a vaginal examination was made, the vault of the vagina had quite healed except for a small granulating patch on the right side. There was a free watery discharge, but the source of this could not be accurately determined.

On May 26 a second vaginal examination was made, and it was now clearly seen that the discharge came from the neighbourhood of the unhealed granulating patch, and that a probe passed into a small sinus lead upwards and to the right for a distance of about one inch. Methylene blue was administered by the mouth, and whilst the urine became stained a deep blue, the discharge was only faintly tinged. Some of this discharge was collected, and an analysis was found to contain a trace of albumin and $0 \cdot 15$ per cent. of urea. On May 31 both the discharge and the urine were analysed for urea, the urine was found to contain 1.85 per cent. and the discharge $0.2 \%$ per cent.

A leucocyte count, done on May 29, gave the following result :Total leucocytes 6,500. Polynuclears 85 per cent., lymphocytes 13 per cent., and large mononuclears 2 per cent.

From May 28 to June 1 the vaginal discharge became considerably less, but on the latter date it again increased for a time, and then gradually diminished until June 12 , when it finally ceased, and concurrently with this cessation the temperature dropped and there was no further rise.

On Tune 29 the abdominal scar was soundly healed and firm, per vaginam there was no thickening to be felt anywhere, and the small granulating patch had almost healed.

The patient was discharged from hospital on June 30.. She attended several times after that date, the last occasion on which I saw her being on September 3, 1908, she was then feeling very well and was quite free from any pain or discomfort. The vagina had quite healed and there was no suspicion of any recurrence.

I have thought this case worth recording on account of the peculiar symptoms which I consider must have been due to some injury of the right ureter at the time of the operation.

The facts that the first symptoms of injury only appeared on the 26 th day after operation, that the onset of the discharge was accompanied by fever, that the three days during which the discharge lessened the temperature fell only to rise again when the discharge increased, and lastly that when the discharge finally ceased the fever also left the patient, appear to me to be very difficult of any satisfactory explanation.

The amount of the discharge and the fact that it contained traces of urea would seem undoubtedly to point to the source being from the urinary tract, the sinus on the right side of the vagina from whence the discharge came, and the marked differences in the amount of urea in the discharge and in the urine from the bladder, would 
seem to point to the fact that the origin was most probably from the right ureter.

As to the exact nature of the injury it seems to be very difficult to hazard an opinion. Neither ureter was seen at the time of operation, and it is hardly possible that one of the ligatures, or stitches could partially or entirely have occluded the ureter without giving rise to symptoms earlier; again there was never at any time the slightest suspicion of sloughing or suppuration either in the vagina or in the urinary tract. The urine was frequently tested, and was always found to be perfectly normal, the vaginal discharge was always clear and sweet, and the leucocyte count on May 29 would seem to negative any suppurative process.

The early fever with rigors following immediately on the operation was undoubtedly due, at least in part, to the septic infection of the abdominal wound culminating in the formation of the abscess, which was ultimately opened and drained, but after this opening there was no fever for 3 days and the temperature only rose again when the discharge commenced.

I think it hardly likely that the rise and fall of temperature with the commencement and cessation of the discharge, was a mere coincidence and, moreover, if the two had no casual connection, it is difficult to understand what the fever was due to.

The case appears to me to be of the most interesting, and at the same time puzzling, nature, and it is for these reasons that I deemed it worthy of record. 


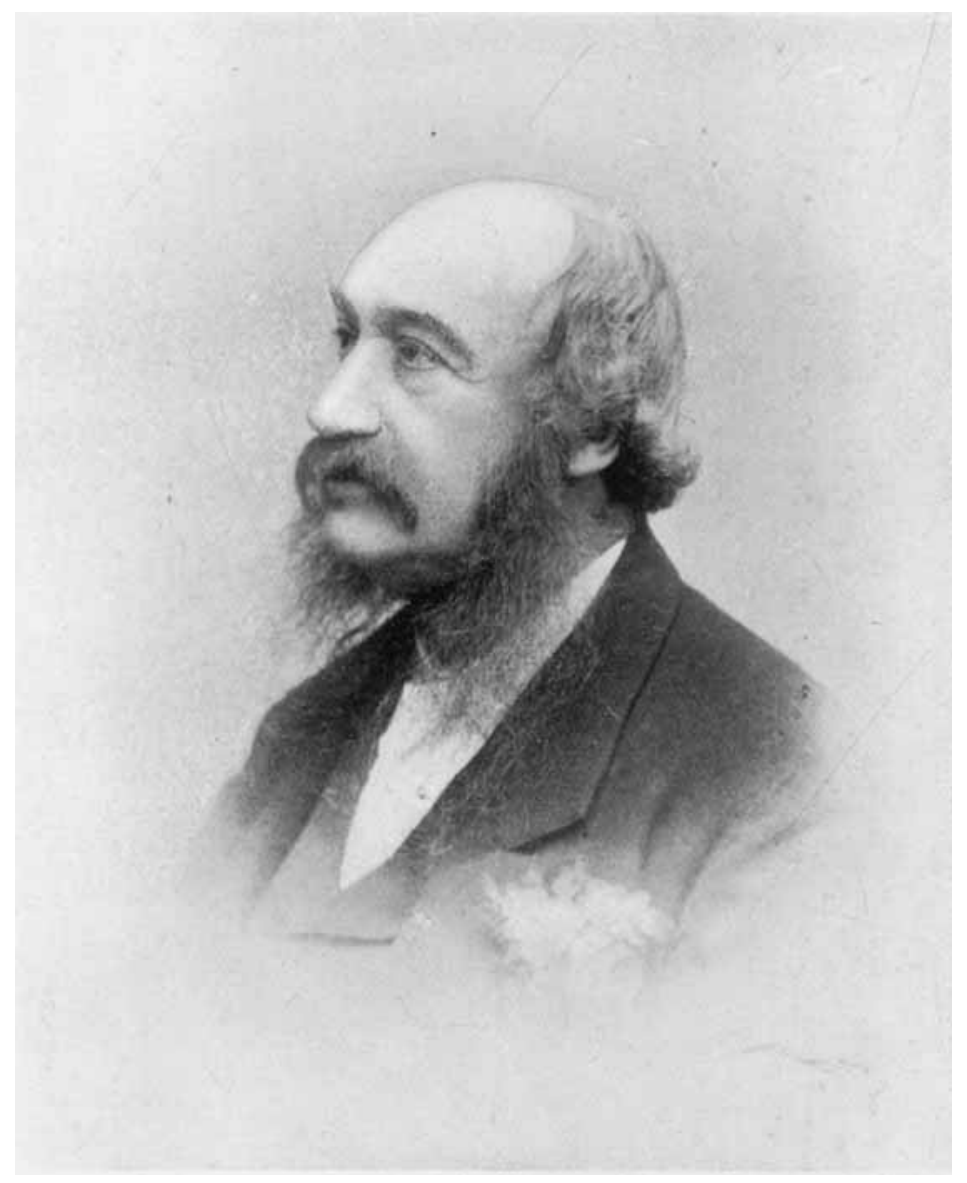

CHARIES HENRY FELIX ROLTH. 